\title{
Oxazole-Based Peptide Macrocycles: A New Class of G- Quadruplex Binding Ligands
}

\author{
Katja Jantos, Raphaël Rodriguez, Sylvain Ladame, Pravin S. Shirude, and Shankar \\ Balasubramanian* \\ The University Chemical Laboratory, University of Cambridge, Lensfield Road, Cambridge CB2 \\ 1EW, U.K.
}

\begin{abstract}
During the past decade, there has been growing interest in the structure, recognition, and function of DNA G-quadruplexes. The best-studied example is the human telomeric quadruplex, which is associated with the inhibition of telomere elongation by telomerase, an enzyme up-regulated in cancer cells.1 Furthermore, a large number of other putative quadruplex forming sequences have been identified in the human genome. 2 We have recently identified a quadruplex forming sequence in the promoter of the c-kit oncogene with potential to regulate the expression of the c-kit gene at the transcription level. $3 \mathrm{We}$ have demonstrated that this quadruplex predominantly exists in a parallel conformation in vitro under near physiological conditions. In contrast, the human telomeric quadruplex has been shown to adopt different conformations in the presence of either sodium or potassium. Structural studies have reported that the human telomeric quadruplex can exist as a parallel, 4 antiparallel,5 or even a mixed-type hybrid structure. 6 Hitherto, chemists have been addressing the design of small molecule ligands that selectively recognize quadruplex DNA in preference to double-stranded DNA. However, owing to the increasing number of quadruplexes being identified in the human genome, an emerging goal is to elucidate quadruplex recognition by small molecules in order to design ligands that can discriminate between quadruplex sequences and/or quadruplex folds. A number of other classes of macrocyclic molecules have been reported in the literature that have shown good potential to bind quadruplexes.7
\end{abstract}

Herein, we report on the quadruplex binding properties of oxazole-based peptide macrocycles of general structure 1 (Figure 1). In particular, we have studied their interaction with the c-kit quadruplex in comparison to the human telomeric quadruplex. Structural studies on related, biologically active cyclopeptides using molecular modeling and X-ray crystallography studies concluded that macrocycles of structure $\mathbf{1}$ are generally planar.8 This information together with a consideration of the size complementarity led us to reason that such structures have potential to recognize quadruplexes via interactions with the top tetrad. The macrocycles 1a-d are chiral and functionalized with alkylamines to provide water solubility and potentially also participate in favorable interactions with the DNA scaffold. As part of the study we have investigated the influence of stereochemical variations as well as the importance of the lateral side chains on quadruplex recognition and stabilization.

Macrocycles of general structure $\mathbf{1}$ were synthesized by assembly of three amino acid building blocks (2, Figure 1) (see Supporting Information). Their potential as G-quadruplex

(C) 2006 American Chemical Society

E-mail: sb10031@cam.ac.uk.

Supporting Information Available: Experimental procedures for the synthesis of the macrocycles 1, SPR binding curves, experimental details for CD and FRET. This material is available free of charge via the Internet at http://pubs.acs.org. 
ligands was first investigated using surface plasmon resonance (SPR), which has proven to be a valuable method to examine DNA-small molecule interactions.7c-d,9 The experiments were performed using three different immobilized DNA targets: two quadruplexes formed from either the human telomeric sequence d(biotin- $\left[\mathrm{GT}_{2} \mathrm{~A}\left(\mathrm{G}_{3} \mathrm{~T}_{2} \mathrm{~A}\right)_{4} \mathrm{G}_{2}\right]$ ) (hTelo) or d(biotin$\left[\mathrm{C}_{3} \mathrm{G}_{3} \mathrm{CG}_{3} \mathrm{CGCGAG}_{3} \mathrm{AG}_{4} \mathrm{AG}_{2}\right]$ ) (c-kit) and a double stranded DNA (ds DNA) comprising the oligonucleotide $\mathrm{d}$ (biotin- $\left[\mathrm{G}_{2} \mathrm{CATAGTGCGTG} \mathrm{CGT}_{2} \mathrm{AGC}\right]$ ) hybridized with its complementary sequence. The results are summarized in Table 1.

It is noteworthy that while ligands 1a-d all bind quadruplex DNA, none of the macrocyles showed detectable binding to double-stranded DNA, even at high ligand concentration (300 $\mu \mathrm{M})$, thus this class of molecules is highly selective for quadruplex as compared to duplex. The enantiomers 1a,b were found to bind hTelo with comparable dissociation constants $\left(K_{\mathrm{D}}\right)$ of 15 and $12 \mu \mathrm{M}$, respectively. The SPR data showed a 1:1 stoichiometry for ligandquadruplex binding, which is suggestive of a specific ligand-quadruplex interaction with a single guanine tetrad as proposed for other classes of quadruplex binding ligands.7 1a,b each contain three butylamine side chains exclusively on one face of the macrocycle, leaving the opposite face unhindered and therefore accessible for $\pi-\pi$ interactions with the top tetrad of the quadruplex. The comparable binding affinities for 1a,b suggest that an inversion of all three stereocenters does not affect homochiral quadruplex structure recognition. However, inversion of only one stereocenter presents side chains on both faces of the macrocycle, which led to a 4- to 6-fold drop in binding affinity for diastereoisomer 1c, as compared to $\mathbf{1 a}$ and $\mathbf{1 b}$, for hTelo and c-kit quadruplexes (Table 1). This result is also consistent with tetrad based quadruplex recognition by 1a,b. Moreover, it is noteworthy that for the macrocycles 1a,b a 3-fold selectivity for c-kit vs hTelo was observed.

Primary amines are protonated at physiological $\mathrm{pH}$ and may be involved in stabilizing interactions with the grooves and loops of the quadruplex as well as the negatively charged phosphate backbone. To evaluate the role of the amine side chains, we prepared macrocycle 1d10 with shorter methylamine side chains. Compared to 1a, macrocycle 1d showed a reduced binding affinity for hTelo (4-fold), but an unchanged equilibrium binding to c-kit. This immediately suggests a different potential for the side chains to recognize each quadruplex.

To strengthen and complement the SPR binding studies, we examined the ability of the macrocycles 1a-d to stabilize G-quadruplex DNA by a fluorescence resonance energy transfer (FRET) assay11 (Figure 2) using dual-labeled hTelo and c-kit quadruplexes, in addition to a double stranded DNA (see Supporting Information). It is noteworthy that FRET melting analysis measures the ligand-induced stabilization of a folded quadruplex, rather than equilibrium binding. For all ligands 1a-d no stabilization of duplex DNA was observed, which is consistent with the SPR observations and confirms the high selectivity for G-quadruplex DNA. For ligands 1a-c the trend for G-quadruplex stabilization effects were consistent with the $K_{\mathrm{D}}$ values obtained by SPR, the tightest binder inducing the strongest thermal stabilization (Table 1). However, macrocycle 1d, which binds to hTelo and c-kit with affinities comparable to that of $\mathbf{1 c}$ and 1a, did not induce a significant thermal stabilization, even at high ligand concentration (up to $50 \mu \mathrm{M}$ ). This suggests that while $\mathbf{1 d}$ binds to c-kit with an affinity comparable to those of ligands 1a-c, its mode of binding does not stabilize (or destabilize) the folded c-kit quadruplex structure.

To provide further insight into the mode of binding we have used circular dichroism (CD) spectroscopy to elucidate ligand effects on the folded conformations of hTelo. In the absence of the ligands, the hTelo oligonucleotide coexists in $\mathrm{K}^{+}$-containing buffer as a mixture of parallel and antiparallel G-quadruplex conformations exhibiting two maxima at 265 and $291 \mathrm{~nm}$ as well as a minimum at $243 \mathrm{~nm}$ (Figure 3, left).12 When hTelo is folded in 
the presence of a 10-fold excess of the respective macrocycle 1, a loss of the antiparallel signal $(291 \mathrm{~nm})$ was observed simultaneously with a significant increase of the band at 265 $\mathrm{nm}$ characteristic of a parallel conformation. This effect was much more pronounced for $\mathbf{1 a}$ ,b, which have been found to be the tightest binders by SPR, than for the weaker binders 1c ,d. Addition of the macrocycle to prefolded hTelo quadruplex did not induce significant change in quadruplex conformation, even after $3 \mathrm{~h}$, suggesting that conformational interconversion is slow. This indicates a thermodynamic preference of macrocycles $\mathbf{1 a - d}$ for binding to a parallel G-quadruplex structure as compared to an antiparallel conformation. The c-kit quadruplex already exists as a predominantly parallel structure in $\mathrm{K}^{+}$-containing buffer and showed no significant change in the CD spectrum upon inclusion of ligands 1a-d (Figure 3, right). These results are consistent with the preference of the macrocycles $\mathbf{1}$ for the predominantly parallel c-kit quadruplex 3 as compared to hTelo which is highly polymorphic. This new class of quadruplex binding ligands represents a versatile and promising scaffold. Further optimization of such structures and an evaluation of biological activity are in progress.

\section{Acknowledgments}

We thank the Gates Cambridge Trust for a studentship (K.J.) and the Cancer Research U.K. for program funding (R.R. and S.L.) and the BBSRC for funding (P.S.). S.B. is a BBSRC Career Development Research Fellow. We also thank Dr. A. Bugaut for careful reading of the manuscript.

\section{References}

1. Zahler AM, Williamson JR, Cech TR, Prescott DM. Nature. 1991; 350:717. [PubMed: 2023635]

2. (a) Huppert JL, Balasubramanian S. Nucleic Acids Res. 2005; 33:2908. [PubMed: 15914667] (b) Todd AK, Johnston M, Neidle S. Nucleic Acids Res. 2005; 33:2901. [PubMed: 15914666]

3. Fernando H, Reszka AP, Huppert J, Ladame S, Rankin S, Venkitaraman AR, Neidle S, Balasubramanian S. Biochemistry. 2006; 45:7854. [PubMed: 16784237]

4. Wang Y, Patel DJ. J. Mol. Biol. 1993; 234:1171. [PubMed: 8263919]

5. Parkinson GN, Lee MPH, Neidle S. Nature (London). 2002; 417:876. [PubMed: 12050675]

6. Ambrus A, Chen D, Dai J, Bialis T, Jones RA, Yang D. Nucleic Acids Res. 2006; 34:2723. [PubMed: 16714449]

7. For recent examples see Dixon IM, Lopez F, Estève J-P, Tejera AM, Blasco MA, Pratviel G, Meunier B. ChemBioChem. 2005; 6:123. [PubMed: 15551357] Seenisamy J, Bashyan S, Gokhale V, Vankayalapati H, Sun D, Siddiqui-Jain A, Steiner AN, Shin-ya K, White E, Wilson WD, Hurley LH. J. Am. Chem. Soc. 2005; 127:2944. [PubMed: 15740131] Teulade-Fichou M-P, Carrasco C, Guittat L, Bailly C, Alberti P, Mergny J-L, David A, Lehn J-M, Wilson WD. J. Am. Chem. Soc. 2003; 125:4732. [PubMed: 12696891] Schouten JA, Ladame S, Mason SJ, Cooper MA, Balasubramanian S. J. Am. Chem. Soc. 2003; 125:5594. [PubMed: 12733873]

8. Lucke AJ, Tyndall JDA, Singh Y, Fairlie DP. J. Mol. Graphics Modell. 2003; 21:341. [PubMed: 12543133]

9. (a) Moore MJB, Schultes CM, Cuesta J, Cuenca F, Gunaratnam M, Tanious FA, Wilson WD, Neidle S. J. Med. Chem. 2006; 49:582. [PubMed: 16420044] (b) Ladame S, Schouten JA, Stuart J, Roldan J, Neidle S, Balasubramanian S. Org. Biomol. Chem. 2004; 2:2925. [PubMed: 15480456]

10. Mink D, Mecozzi S, Rebek J Jr. Tetrahedron Lett. 1998; 39:5709.

11. Mergny J-L, Maurizot J-C. ChemBioChem. 2001; 2:124. [PubMed: 11828436]

12. Rezler EM, Seenisamy J, Bashyam S, Kim M-Y, White E, Wilson WD, Hurley LH. J. Am. Chem. Soc. 2005; 127:9439. [PubMed: 15984871] 


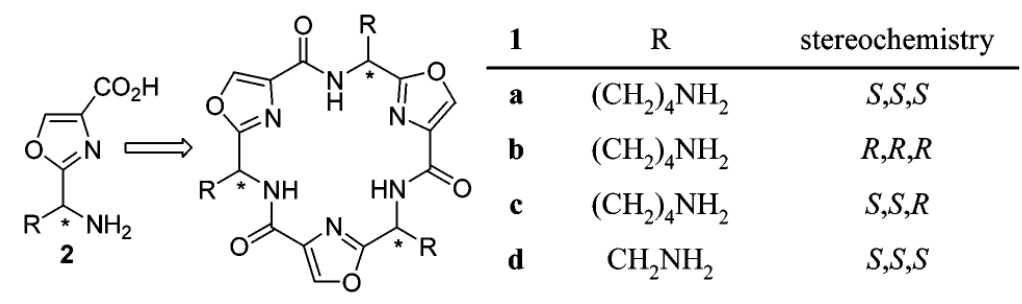

Figure 1.

Structures of oxazole-based peptide macrocycles $\mathbf{1 a}-\mathbf{d}$. 

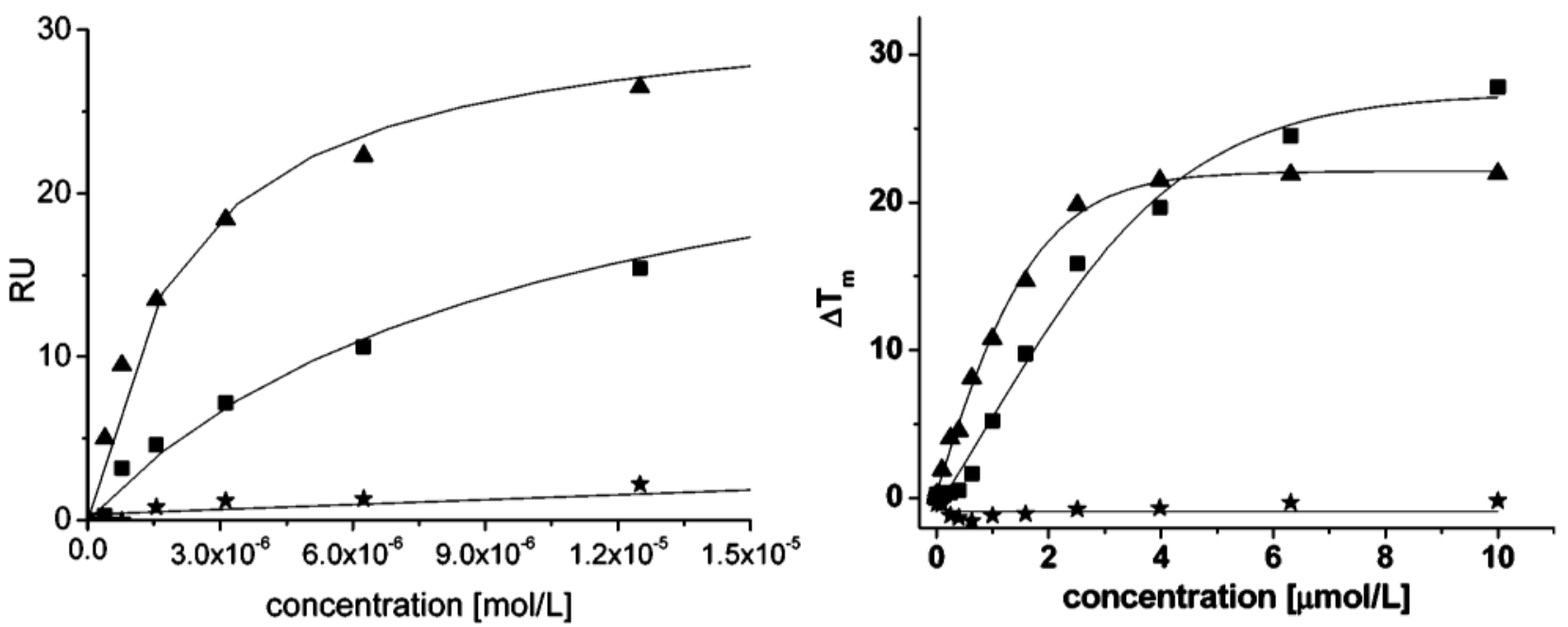

Figure 2.

(left) SPR binding curve for macrocycle 1a to hTelo $(\boldsymbol{\square})$, c-kit $(\boldsymbol{\Delta})$, and ds DNA ( ); running-buffer, $50 \mathrm{mM}$ Tris $\cdot \mathrm{HCl} \mathrm{pH}$ 7.4, $100 \mathrm{mM} \mathrm{KCl}$. (right) FRET assay for hTelo (ם), ckit $(\boldsymbol{\Delta})$, and ds DNA $(\star)$ in the presence of 1a; buffer, $60 \mathrm{mM}$ potassium cacodylate $\mathrm{pH}$ 7.4. 

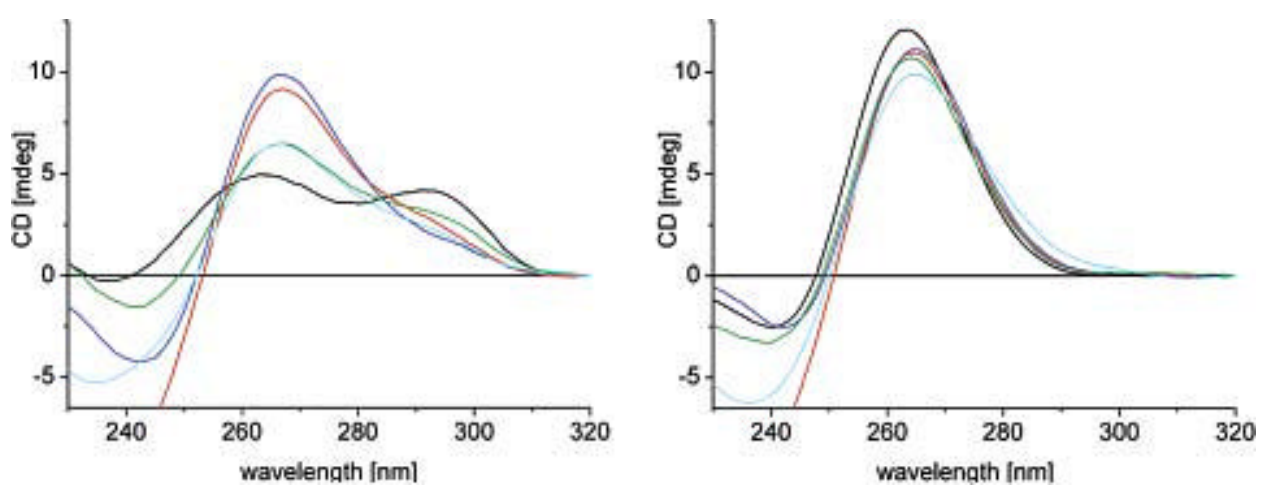

Figure 3 .

CD spectra of hTelo (left) and c-kit (right) in $\mathrm{K}^{+}$containing buffer $(50 \mathrm{mM}$ Tris. $\mathrm{HCl} \mathrm{pH} 7.4$, $100 \mathrm{mM} \mathrm{KCl}$ ): without ligand (black); folded in the presence of $\mathbf{1 a}$ (red), $\mathbf{1 b}$ (blue), 1c (green), and 1d (cyan). 


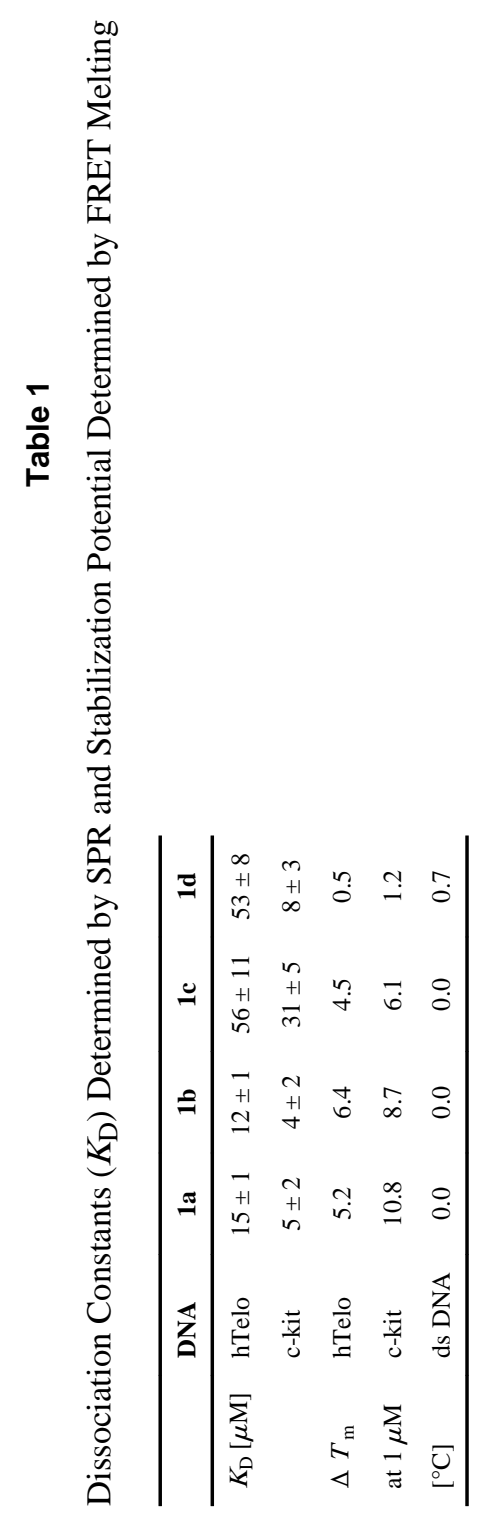

J Am Chem Soc. Author manuscript; available in PMC 2008 January 14. 